\title{
HLA and sexually transmitted diseases in prostitutes
}

\author{
S. H. CHAN,* TUliP TAN,t Ali KAMARUDIN, † G. B. WEE,* AND V. S. RAJAN† \\ From the *Department of Microbiology, Faculty of Medicine, University of Singapore, and + Middle \\ Road Hospital, Singapore
}

SUMMARY The HLA profile of 148 unrelated, Chinese prostitutes (56 with repeated gonococcal infection, 31 with syphilis, 31 with gonorrhoea and syphilis, and 30 with no evidence of infection) was compared with that of 238 unrelated, healthy, Chinese control subjects. The joint occurrence of AW19 B17 was observed in $25 \cdot 8 \%$ of prostitutes with double infections compared with $6 \cdot 7 \%$ of control subjects, while that of A11 B15, on the other hand, was associated with a resistance to syphilis and gonorrhoea. The latter profile was observed in $46.7 \%$ of prostitutes in business for more than two years who were resistant to disease, in $30 \%$ of prostitutes with an overall disease resistance, in $13.4 \%$ of control subjects, and in only $3.2 \%$ of prostitutes with combined syphilis and gonorrhoea. Because of the statistical uncertainty when multiple variables are being analysed these studies should be repeated in other groups of prostitutes of the same and different ethnic origins.

\section{Introduction}

Prostitutes are the major source of sexually transmitted diseases in Singapore (Khoo et al., 1977). Some prostitutes have repeated infections while others are quite resistant to infection. While exposure to the causative organisms is an obvious explanation, another reason may be the differences in the immune response of the host to these organisms. The control of immune responses to synthetic antigens by immune response (IR) genes associated with the major histocompatibility locus has been clearly demonstrated in animals (Snell et al., 1976). Recently, there has been evidence which suggests that IR genes associated with the major histocompatibility locus (HLA) may also exist in man (Blumenthal et al., 1964; McMichael and McDevitt, 1977; Vries et al., 1977). Thus, if the functions of immune response genes influence the susceptibility or resistance to venereal disease organismis in these prostitutes, these differences may be reflected in their HLA profiles. The results of HLA typing in prostitutes who are susceptible to and in those who are resistant to venereal diseases are reported in this paper.

Address for reprints: Dr S. H. Chan, WHO Immunology Training Centre, Faculty of Medicine, University of Singapore, Sepoy Lines, Singapore 3

Received for publication 15 August 1978

\section{Material and methods}

\section{STUDY POPULATION}

A total of 148 unrelated, Chinese, female prostitutes were HLA-typed and the HLA profile compared with that of 238 unrelated, healthy, Chinese, control subjects. The control group consisted of normal, healthy babies born consecutively at a maternity hospital in Singapore over a period of nine months. Both parents were of Chinese ethnic origin, the same ethnic group as the prostitutes. All the prostitutes, who carry medical cards which are regularly checked, are seen at the Middle Road Hospital every two weeks for periods ranging from one to 20 years. Cervical and rectal swabs for culture of gonococci are taken at every visit, and serological tests for syphilis (Venereal Disease Research Laboratory and fluorescent treponemal antibody absorption tests) are performed every three months.

The prostitutes were subdivided into four groups; the ages and the time of exposure to infection of each group is given in Table 1.

\section{Group 1}

This group consisted of 56 patients with repeated gonococcal infections diagnosed by positive culture results. The average number of infections was $5 \cdot 4$ per year per patient, ranging from two to 24 infections per year, and the average interval before the first infection was 3.4 months. 
Table 1 Details of age and exposure to infection of 148 Chinese prostitutes

\begin{tabular}{llllll}
\hline & \multicolumn{2}{l}{ Age (years) } & & \multicolumn{2}{l}{ Exposure to infection (years)* } \\
\cline { 2 - 3 } \cline { 5 - 6 } Patient group & Mean & Range & & Mean & Range \\
\hline 1 & $35 \cdot 8$ & $18-53$ & & $5 \cdot 5$ & $1-17$ \\
2 & $39 \cdot 3$ & $23-55$ & & 10 & $1-20$ \\
3 & $37 \cdot 3$ & $24-56$ & & $6 \cdot 7$ & $1-20$ \\
4 & $32 \cdot 5$ & $19-52$ & & $4 \cdot 3$ & $1-20$ \\
\hline
\end{tabular}

* Estimated from the date each patient became a prostitute to the time of the study

\section{Group 2}

This group consisted of 31 patients with latent syphilis who had been treated and at the time of the study had no symptoms or signs of infection.

\section{Group 3}

This group consisted of 31 patients with combined infections. Serological tests for syphilis and repeated cultures for gonococci both gave positive results. The average number of infections was $\mathbf{4 . 2}$ per year per patient, ranging from two to nine per year, and the average interval before the first infection was four months.

\section{Group 4}

This group consisted of 30 patients who had been exposed to gonorrhoea and syphilis for at least one year but were resistant to infection.

HLA TYPING

HLA typing was performed using the NIH (National Institutes of Health) lymphocyte micro-cytotoxicity method (National Institute of Allergy and Infectious Diseases, 1976-77). A total of 196 antisera defining 26 specificities were used. HLA typing sera were obtained from our own laboratory, the NIH serum bank, and direct from other laboratories. The sera defining A11, AW19, B15, and B17 are listed in Table 2.

Table 2 Antisera used to define A11, AW19, B15, and B17

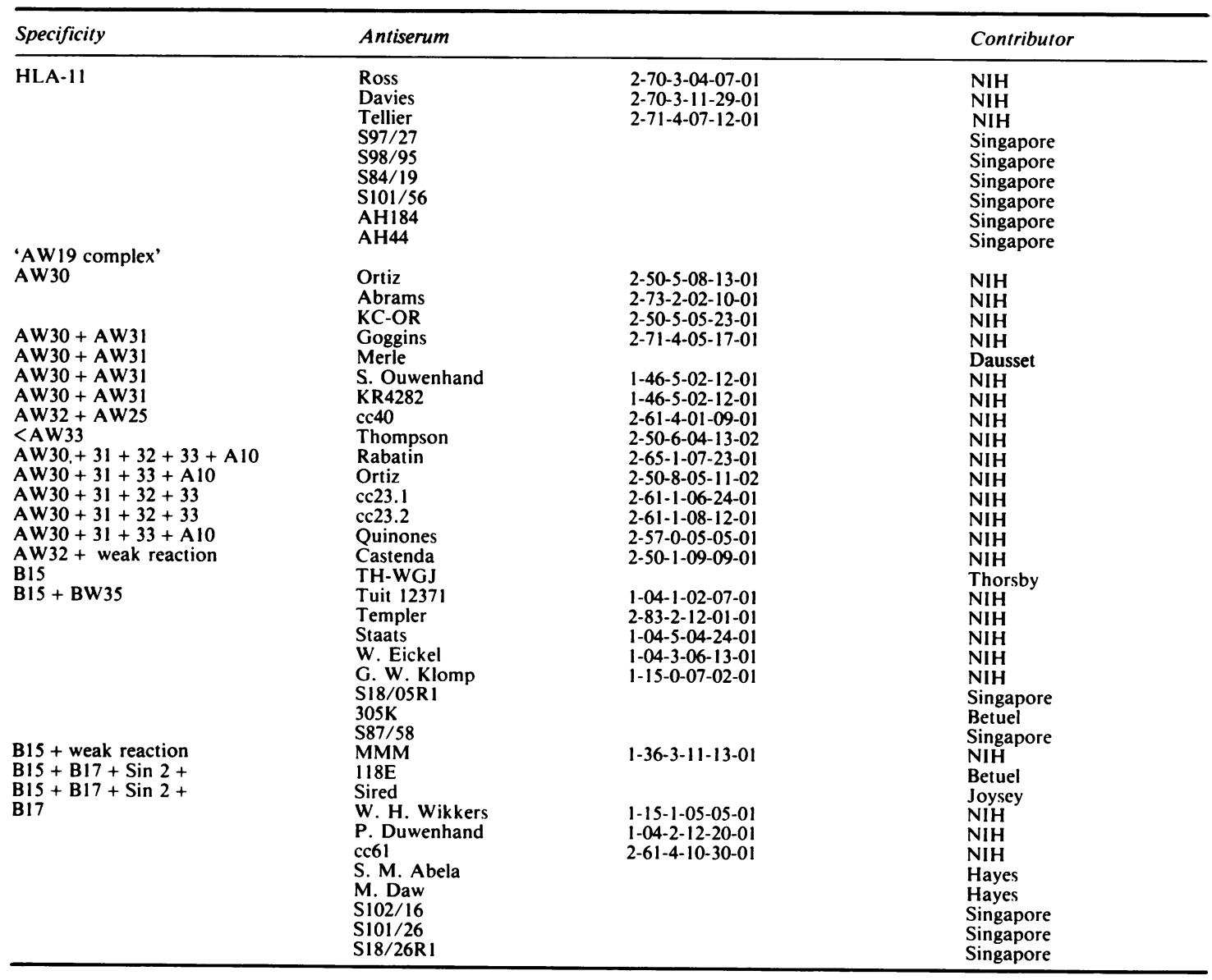


Results

The HLA antigen frequencies of the various groups of prostitutes and controls are shown in Table 3. The frequency of BW46 was significantly higher in the group with gonorrhoea and syphilis combined (group 3) whereas that of A2 was significantly lower in the resistant group (group 4) when compared with the controls. This difference, however, was not significant when corrected for the number of antigens typed.

Certain HLA-A-locus antigens occurred more frequently than expected with a specific B-locus antigen, a situation termed 'linkage disequilibrium'. The joint occurrences of AW19 B17 and A11 B15 in the various groups of prostitutes and in the controls are shown in Table 4. The joint occurrence of AW19 B17 was seen in eight $(25 \cdot 8 \%)$ out of 31 prostitutes with gonorrhoea and syphilis combined compared with $16(6 \cdot 7 \%)$ out of 238 controls $\left(\chi^{2}=12 \cdot 29\right.$; $\mathrm{P}<0.0005$; relative risk $=4 \cdot 83)$. The joint occurrence of A11 B15, on the other hand, was observed in nine $(30 \%)$ out of 31 prostitutes resistant to disease compared with $32(13.4 \%)$ out of 238 controls $\left(\chi^{2}=5 \cdot 16 ; \mathrm{p}<0.025\right)$ and one $(3 \cdot 2 \%)$ out of 31 prostitutes with combined infections $\left(\chi^{2}=5 \cdot 84\right.$; $P<0.025)$. Of the 30 prostitutes who were resistant to disease, 15 had been exposed for more than two years; of these 15, A11 B15 was observed in seven $(46.7 \%)$ patients. The differences in the frequency of A11 B15 between this subgroup of prostitutes (exposed for more than two years and yet resistant to disease) and the controls $\left(\chi^{2}=11.9 ; p<0.001\right)$ and prostitutes with double infections $(P=0 \cdot 0008)$ were even more pronounced.

\section{Discussion}

Caution must be exercised in interpreting the significance of a joint occurrence of antigens from two linked loci, since a large number of combinations (180 in this instance) are possible, and significant

Table 3 Frequencies of $H L A$ in Chinese prostitutes and controls

\begin{tabular}{|c|c|c|c|c|c|c|}
\hline \multirow[b]{2}{*}{$H L A$} & \multicolumn{6}{|l|}{ Prostitutes } \\
\hline & $\begin{array}{l}\text { With gonorrhoea } \\
\text { (group } 1, n=56 \text { ) }\end{array}$ & $\begin{array}{l}\text { With syphilis } \\
\text { (group 2, } n=31 \text { ) }\end{array}$ & $\begin{array}{l}\text { With gonorrhoea } \\
\text { and syphilis } \\
\text { (group 3, } n=31 \text { ) }\end{array}$ & $\begin{array}{l}\text { Total no. } \\
\text { infected } \\
(n=118)\end{array}$ & $\begin{array}{l}\text { Total no. } \\
\text { resistant } \\
\text { (group } 4, n=30)\end{array}$ & $\begin{array}{l}\text { Controls } \\
(n=238)\end{array}$ \\
\hline Al & 0 & $6 \cdot 5$ & 0 & $1 \cdot 7$ & 0 & 0 \\
\hline 2 & $62 \cdot 5$ & $58 \cdot 1$ & $61 \cdot 3$ & $61 \cdot 0$ & $30 \cdot 0^{*}$ & $52 \cdot 9$ \\
\hline 3 & 0 & $3 \cdot 2$ & $3 \cdot 2$ & $1 \cdot 7$ & $3 \cdot 3$ & 0.4 \\
\hline 9 & $32 \cdot 1$ & $32 \cdot 3$ & $35 \cdot 5$ & $33 \cdot 1$ & $43 \cdot 3$ & $27 \cdot 3$ \\
\hline 10 & $5 \cdot 4$ & $3 \cdot 2$ & $9 \cdot 7$ & $5 \cdot 9$ & $6 \cdot 7$ & $5 \cdot 0$ \\
\hline 11 & $48 \cdot 2$ & $58 \cdot 1$ & $45 \cdot 2$ & $50 \cdot 0$ & $60 \cdot 0$ & $60 \cdot 5$ \\
\hline 28 & $1 \cdot 8$ & 0 & 0 & 0.8 & 0 & 0.4 \\
\hline 29 & $1 \cdot 8$ & 0 & $3 \cdot 2$ & $1 \cdot 7$ & $3 \cdot 3$ & $1 \cdot 3$ \\
\hline AW 19 & $17 \cdot 9$ & $9 \cdot 7$ & $32 \cdot 3$ & $19 \cdot 5$ & $23 \cdot 3$ & $20 \cdot 6$ \\
\hline B5 & $10 \cdot 7$ & $9 \cdot 7$ & $9 \cdot 7$ & $10 \cdot 2$ & $13 \cdot 3$ & $12 \cdot 6$ \\
\hline 7 & $1 \cdot 8$ & 0 & $3 \cdot 2$ & $1 \cdot 7$ & $3 \cdot 3$ & $1 \cdot 7$ \\
\hline 8 & 0 & 0 & 0 & 0 & 0 & 0.4 \\
\hline 12 & $1 \cdot 8$ & $3 \cdot 2$ & 0 & $1 \cdot 7$ & $6 \cdot 7$ & $3 \cdot 4$ \\
\hline 13 & $16 \cdot 1$ & $16 \cdot 1$ & $16 \cdot 1$ & $16 \cdot 2$ & $23 \cdot 3$ & $20 \cdot 2$ \\
\hline 14 & 0 & 0 & 0 & 0 & 0 & 0 \\
\hline 15 & $32 \cdot 1$ & $29 \cdot 0$ & $22 \cdot 6$ & $28 \cdot 8$ & $33 \cdot 3$ & $22 \cdot 3$ \\
\hline 17 & $17 \cdot 9$ & $12 \cdot 9$ & $25 \cdot 8$ & $18 \cdot 6$ & $13 \cdot 3$ & $14 \cdot 3$ \\
\hline 18 & 0 & 0 & 0 & 0 & 0 & $1 \cdot 7$ \\
\hline 27 & $3 \cdot 6$ & $6 \cdot 5$ & $5 \cdot 1$ & $5 \cdot 1$ & 0 & $7 \cdot 1$ \\
\hline 37 & $1 \cdot 8$ & 0 & 0 & $0 \cdot 8$ & 0 & 0.4 \\
\hline 40 & $36 \cdot 4$ & $35 \cdot 5$ & $32 \cdot 3$ & $34 \cdot 7$ & $38 \cdot 7$ & $40 \cdot 0$ \\
\hline BW 16 & $16 \cdot 1$ & $16 \cdot 1$ & $16 \cdot 1$ & $16 \cdot 1$ & $9 \cdot 7$ & $10 \cdot 0$ \\
\hline 21 & 0 & 0 & 0 & 0 & 0 & 0 \\
\hline 22 & $5 \cdot 4$ & $9 \cdot 7$ & $16 \cdot 1$ & $9 \cdot 3$ & $10 \cdot 0$ & $12 \cdot 2$ \\
\hline 35 & $10 \cdot 7$ & $6 \cdot 5$ & 0 & $6 \cdot 8$ & 0 & $4 \cdot 6$ \\
\hline 46 & $28 \cdot 6$ & $25 \cdot 8$ & $38 \cdot 7^{*}$ & $30 \cdot 5$ & $13 \cdot 3$ & $22 \cdot 7$ \\
\hline
\end{tabular}

*In comparison of patient group with controls $P \leqslant 0 \cdot 05$ 
Table 4 Joint occurrences of locus $A$ and $B$ antigens in various groups of prostitutes and in the controls

\begin{tabular}{|c|c|c|c|c|c|c|c|c|c|c|}
\hline \multirow{3}{*}{ Antigen } & \multicolumn{10}{|c|}{ Prostitutes } \\
\hline & \multicolumn{2}{|c|}{$\begin{array}{l}\text { With gonorrhoea } \\
(n=56)\end{array}$} & \multicolumn{2}{|c|}{$\begin{array}{l}\text { With syphilis } \\
(n=3 I)\end{array}$} & \multicolumn{2}{|c|}{$\begin{array}{l}\text { With gonorrhoea and } \\
\text { syphilis } \\
(n=3 I)\end{array}$} & \multicolumn{2}{|c|}{$\begin{array}{l}\text { Resistant } \\
(n=30)\end{array}$} & \multicolumn{2}{|c|}{$\begin{array}{l}\text { Controls } \\
(n=238)\end{array}$} \\
\hline & No. & $\%$ & No. & $\%$ & No. & $\%$ & No. & $\%$ & No. & $\%$ \\
\hline $\begin{array}{l}\text { AW19 B17 } \\
\text { A11 B15 }\end{array}$ & $\begin{array}{r}5 \\
10\end{array}$ & $\begin{array}{r}8.9 \\
17.9\end{array}$ & $\begin{array}{l}2 \\
4\end{array}$ & $\begin{array}{r}6 \cdot 5 \\
12 \cdot 9\end{array}$ & $\begin{array}{l}8 \\
1\end{array}$ & $\begin{array}{c}25 \cdot 8^{*} \\
3 \cdot 2\end{array}$ & $\begin{array}{l}2 \\
9\end{array}$ & $\begin{array}{l}6 \cdot 7 \\
30 \cdot 0+\end{array}$ & $\begin{array}{l}16 \\
32\end{array}$ & $\begin{array}{r}6 \cdot 7 \\
13 \cdot 4\end{array}$ \\
\hline
\end{tabular}

- Difference between patient group and controls, $\chi^{2}=12 \cdot 97 ; \mathrm{P}<0.0005$; relative risk $=4.83$

+ Difference between patient group and controls, $\chi^{2}=5 \cdot 64 ; \mathrm{P}<0 \cdot 025 ;$ cross product $=2 \cdot 76$

associations may be detected by chance. In fact, after correction for the number of combinations tested $(P$ value $\times 180$ ) none of the $P$ values are significant. Because the correct method of statistical analysis for this type of data, however, is by no means established, further studies are clearly necessary, since our study suggests that there may be HLA associations both in the susceptibility and in the resistance to venereal disease in prostitutes. The association appeared to be with the joint occurrence of A-locus and B-locus antigens. The frequency with which AW19 B17 occurred was significantly higher in prostitutes with both gonorrhoea and syphilis $(25 \cdot 8 \%)$ than in normal controls $(6 \cdot 7 \%)$ or other groups of prostitutes.

The joint occurrence of A11 B15 was more frequent among prostitutes who were resistant to disease $(30 \%)$ than in controls $(13 \cdot 4 \%)$. The association of A11 B15 within the resistant group was even stronger when only those uninfected prostitutes who had been in business for over two years were included in the group $(46 \cdot 7 \%)$. On the other hand, the frequency with which A11 B15 occurred was very low among prostitutes with double infections $(3 \cdot 2 \%)$. It thus appears that A11 B15 was associated with a resistance to syphilis and gonorrhoea. Direct evidence of exposure to syphilitic and gonococcal organisms in this group of prostitutes would be difficult to obtain. This group of prostitutes operates in the same area as the other groups, and all the prostitutes in this group had been in business for more than a year, $(15(50 \%)$ out of 30 for more than two years and $10(33 \%)$ out of 30 for more than five years). Singapore is also a major port and tourism is one of its main industries. It seems likely, therefore, that this group had been exposed to syphilis and gonorrhoea.

Confirmation of the joint occurrences of A-locus and B-locus antigens would suggest that the genes which influence disease susceptibility and resistance are present in linkage disequilibrium with the major histocompatibility locus genes. These genes may be immune-response genes modifying the host's response to these sexually transmissible organisms, though other possibilities, such as genes which regulate the biochemical factors in vaginal secretions which prevent bacterial colonisation-for example, $\mathrm{pH}$ or lysozyme content-must be considered. If IR genes are concerned it may be possible to confirm this hypothesis by using assays of cellular immune response to gonococcal and treponemal antigens in vitro. Though these results may not have immediate clinical significance, it is possible that they could lead to new immunotherapeutic approaches to infectious diseases in general.

This study was supported in part by research funds from WHO IRTC Singapore. The authors wish to thank Drs Betuel, Dausset, Hayes, Joysey, Thorsby, and Payne and the NIH serum bank for kind donations of HLA typing sera.

\section{References}

Blumenthal, M. N., Amos, D. B., Noreen, H., Mendell, N. Y., and Yunis, E. J. (1964). Genetic mapping of IR locus in man: Linkage to second locus of HLA. Science, 184, 1301.

Khoo, R., Sng, E. H., and Goh, A. J. (1977). A study of sexually transmitted diseases in 200 prostitutes in Singapore. Asian Journal of Infectious Diseases, 1, 77-80.

McMichael, A. and McDevitt, H. (1977). The association between the HLA system and disease. In Progress in Medical Genetics II, edited by A. G. Steinberg, A. G. Bearn, A. G. Motulsky, and B. Childe. W. B. Saunders Co: Philadephia.

National Institute of Allergy and Infectious Diseases (1976-77). Manual of Tissue-typing Technique. Edited by J. G. Tay, D. B. Hare, P. D. Pedersen, and D. I. Mullally. US Department of Health, Education and Welfare Publication no. 76-545, p. 22. US Printing Office: Washington DC.

Snell, G. D., Dausset, J., and Nathenson, S. (1976). Histocompatibility. Academic Press Inc: New York.

Vries, R. R. P., Kreetenberg, H. G., Locgen, H. G., and van Rood J. J. (1977). In vitro immune responsiveness to vaccine virus and HLA. New England Journal of Medicine, 297, 692-696. 